Selcuk Journal of Agriculture and Food Sciences

http://sjafs.selcuk.edu.tr/sjafs/index

Research Article
SJAFS

(2021) 35 (3), 265-271

e-ISSN: 2458-8377

DOI:10.15316/SJAFS.2021.256

\title{
An Application of Fuzzy Pearson Correlation Methods in Animal Sciences
}

\author{
DDerviş TOPUZ ${ }^{1 *}$, iD İsmail KESKİN ${ }^{2}$ \\ ${ }^{1}$ Niğde Ömer Halisdemir University, Niğde Zübeyde Hanım Vocational School of Health Services, Department of \\ Health Services Science, Niğde, Turkey \\ ${ }^{2}$ Selcuk University, Faculty of Agriculture, Department of Animal Science, Konya, Turkey
}

\begin{tabular}{|c|c|}
\hline ARTICLE INFO & ABSTRACT \\
\hline $\begin{array}{l}\text { Article history: } \\
\text { Received date: } 26.04 .2021 \\
\text { Accepted date: } 21.09 .2021\end{array}$ & $\begin{array}{l}\text { How to evaluate an appropriate correlation to find the fuzzy relationship be- } \\
\text { tween variables is an important topic in the lactation milk yield and reproduc- } \\
\text { tion characteristics measurement. Especially when the data illustrate uncertain, }\end{array}$ \\
\hline $\begin{array}{l}\text { Keywords: } \\
\text { Holstein Friesian cows } \\
\text { Lactation Milk Yield } \\
\text { Reproductive Properties, } \\
\text { Fuzzy logic } \\
\text { Fuzzy Pearson correlation coefficient }\end{array}$ & $\begin{array}{l}\text { features that help resolving unclear thinking in human logic and the source of } \\
\text { uncertainties in the natural structure of the data. Traditionally, we use Pear- } \\
\text { son's Correlation Coefficient to measure the correlation between data with real } \\
\text { value. However, when the data are composed of fuzzy numbers, it is not feasi- } \\
\text { ble to use such a traditional approach to determine the fuzzy correlation coeffi- } \\
\text { cient. This study proposes the calculation of fuzzy correlation with triangular } \\
\text { of fuzzy data. Using Matlab application, fuzzy Pearson correlation coefficients } \\
\text { and their membership degrees which belong to Holstein Friesian cows for the } \\
\text { relationship between lactation milk yield, the age of the animal at lactation, } \\
\text { number of days milked, service period and first calving age were calculated (- } \\
0.0056 \text {; } 0.95) \text {, ( } 0.1419 \text {; } 0.98) \text {, (-0.272; } 1.0) \text { and }(-0.2543 \text {; } 0.90) \text { respectively. } \\
\text { The membership degrees of the calculated fuzzy Pearson coefficient values are } \\
\text { more reliable and a consistent coefficient since it determines the size of the } \\
\text { relationship between the sets, which belong to variables. } \\
\text { As a result of the study, the fuzzy Pearson correlation coefficient analysis may } \\
\text { be preferred to calculate the degree of uncertainty and membership degrees } \\
\text { between variables that should be used in studies to increase lactation milk } \\
\text { yield. }\end{array}$ \\
\hline
\end{tabular}

\section{Introduction}

In recent years, fuzzy logic and fuzzy logic based applications have become an important subject in many fields of science and contributed to the development of alternative statistical methods. Increased knowledge and rapid developments in the field of technology lead to radical and continuous changes in human life. It has been the aim of all societies to keep up with this change and not to be left behind, or to solve problems from inaccurate thoughts or ambiguities in terms of information about the event or the case, which contains many uncertainties. The information obtained is not sufficient, reliable, in all cases, so that an event can be fully understood and interpreted, it is often necessary to reach the result through knowledge and thinking. Instead of being unstable where the integrity of the available information cannot be achieved, researchers obtain accurate and reliable results by adding experiences and thoughts to the process (Şentürk \& Aşan 2007). However, since most of the information used in real life has

\footnotetext{
*Corresponding author email: topuz@ohu.edu.tr
}

a generally fuzzy structure, it is obvious that everything is facing a grading problem.

Fuzzy logic theory actually mimics man-specific behavior. Naturally, an uncertainty can be easily recognized when expressing information that can be verified based on any scientific data (Paksoy et al 2013). For example, while a person engaged in animal husbandry uses "cold", "normal", "hot" etc, compound fuzzy expressions consist of linguistic variables such as "too cold", "normal", "too hot". In order to solve many uncertainties in the natural structure of this kind of data, it has been shown that in almost every field today, new alternative statistical approaches can be obtained with more reliable and consistent results (Xie \& Wu 2012). In this study, the calculation of fuzzy Pearson's correlation coefficient with triangular fuzzy data was demonstrated.

This study was conducted to determine the relationships between lactation milk yield and reproductive characteristics using fuzzy Pearson correlation analysis.

\section{Materials and Methods}




\section{Material}

The material of the study was composed of 138 cows of Holstein Friesian cows reared in a private enterprise in Develi, Kayseri. The relationships between lactation milk yield and service period, gestation period and first calving age of these cows were calculated by using fuzzy Pearson correlation coefficient. Calculation method and the mean fuzzy correlation coefficient value for each coefficient were compared by creating confidence intervals. Also fuzzy standard error values, such as fuzzy statistics values are calculated for 138 head Holstein Friesian cows. Data collection with the animal care and breeding practices from the enterprise were used in this study in compatible with animal welfare rules stated in Article 9 in government law of Turkey (No.5996).

For analyses EXCEL 2016, Matlab R2013a and SPSS for WINDOWS Version 24.0 were used.

\section{Method}

\section{Classic and Fuzzy Cluster}

It is a set of clusters that is developed on the logic of any set of elements belonging to the properties that are examined on classic clusters or which is not the element of the cluster. This type of cluster requires characteristic functions to reveal the shape of the distribution of random variables. So classic clusters, $f_{B}(x)$ are defined with characteristic functions (Tanaka \& Guo 1999).

Using the characteristic function, each element examined is assigned only one of the values 0 and 1 ( $\mathrm{Za}-$ deh 1965). It is possible to define the characteristic function of the B as;

$$
f_{B}(x)=\left\{\begin{array}{lll}
1, & x \in B & \text { if } \\
0, & x \notin B & \text { if }
\end{array}\right\}
$$

Here $f_{B}(x): E \rightarrow\{0,1\} \rightarrow R$ (set of real numbers is the characteristic (membership) function of cluster $\mathrm{B}$, which is a subset of the universal cluster (Zadeh 1965; Ross 2004; Tansu 2012; Bede 2013; Trillas \& Eciolaza 2015).

Each element in the cluster either belongs to a cluster or not. Partial membership is never allowed, hence the classic set theory identifies the boundaries of the clusters and the properties of the elements of the cluster. However, the limits of any set to be formed in practice and the general characteristics of the elements that will form this cluster cannot always be determined precisely. In such cases, it is clear that the basic knowledge of classical set theory is insufficient to classify some uncertainties in our daily lives.

To solve such situations, there is a need for different scientific methods with basic knowledge that can measure the linguistic uncertainty of words or groups of words used in a very complex or unambiguously defined language of life. Membership functions that use fuzzy numbers objectively are created to examine the uncertainty of scientific methods needed. With these membership functions, many ambiguities can be expressed mathematically and the values of the variables can be evaluated numerically (Zadeh 1978).

Fuzzy sets membership functions with expressed $\mu_{\widetilde{\mathrm{B}}}\left(\mathrm{x}_{\mathrm{i}}\right)$ is the cluster type and they form the basis of fuzzy set theory. Quantitative variables are made more meaningful by giving membership degrees with the help of membership functions. Membership function $\mu_{\widetilde{\mathrm{B}}}\left(\mathrm{x}_{\mathrm{i}}\right)$, is the degree of belonging of the cluster belonging to any fuzzy set. $\mu_{\widetilde{\mathrm{B}}}\left(\mathrm{x}_{\mathrm{i}}\right): \mathrm{E} \rightarrow[0.0,1.0]$ the mathematical function that corresponds to a number with various degrees of membership is called " $\mathrm{mem}$ bership function" (Zimmermann 1996; Tanaka 1997; Nguyen \& Wakler 2000; Bede 2013). Values calculated with the help of membership functions are also called membership degrees (Zadeh 1978). The degree of membership refers to the degree to which any object is a member of the universal cluster.

For example, let $E=\left\{x_{i} \mid i=1,2, ., n\right\}$ a fuzzy universal cluster. In this universal cluster, fuzzy $\widetilde{B}$ subset is defined as:

$\widetilde{\mathrm{B}}=\left\{\left(\mathrm{x}_{1}, \mu_{\widetilde{\mathrm{B}}}\left(\mathrm{x}_{1}\right)\right),\left(\mathrm{x}_{2}, \mu_{\widetilde{\mathrm{B}}}\left(\mathrm{x}_{2}\right)\right), \ldots,\left(\mathrm{x}_{\mathrm{n}}, \mu_{\widetilde{\mathrm{B}}}\left(\mathrm{x}_{\mathrm{n}}\right)\right) \mid \mathrm{x}_{\mathrm{n}}, \mu_{\widetilde{\mathrm{B}}}\left(\mathrm{x}_{\mathrm{n}}\right) \mathrm{x} \in \mathrm{E}\right\}$

Here $\mu_{\widetilde{\mathrm{B}}}\left(\mathrm{x}_{\mathrm{i}}\right)$ : blurred clusters are members. $\widetilde{\mathrm{B}}$ is the value that indicates how much each $\mathrm{x}_{\mathrm{i}}$ element belongs to the $\widetilde{B}$ fuzzy set (Chiang \& Lin 2000). It is identified as in Equality at 3 (Zadeh 1965; Abdalla 2012; Atanassov 2012);

$\mu_{\widetilde{\mathrm{B}}}\left(\mathrm{x}_{\mathrm{i}}\right)=\left\{\begin{array}{cc}\mu_{\widetilde{\mathrm{B}}}\left(\mathrm{x}_{\mathrm{i}}\right)=1 \text { if, } & \mathrm{x}_{\mathrm{i}} \text { completely } \widetilde{\mathrm{B}} \text { is a member of the cluster } \mathrm{x}_{\mathrm{i}} \in \widetilde{\mathrm{B}} \\ 0<\mu_{\widetilde{\mathrm{B}}}\left(\mathrm{x}_{\mathrm{i}}\right)<1 \text { if, } & \mathrm{x}_{\mathrm{i}} \text { partially } \widetilde{\mathrm{B}} \text { is a member of } \\ \mu_{\widetilde{\mathrm{B}}}\left(\mathrm{x}_{\mathrm{i}}\right)=0 \text { if, } & \mathrm{x}_{\mathrm{i}} \widetilde{\mathrm{B}} \text { is not a member of } \mathrm{x}_{\mathrm{i}} \notin \widetilde{\mathrm{B}}\end{array}\right\}$

Membership degree $\mu_{\widetilde{B}}\left(x_{i}\right)$ with a value close to 1 is a high order element of the cluster and a membership degree close to 0 is the lower element of this cluster (Sakawa 1993).

In order to solve the many uncertainties encountered in determining the degree of relations between the clusters, it is tried to show that more reliable and consistent results can be obtained by using the alternative fuzzy Pearson correlation coefficient calculation method.

\section{Fuzzy Pearson Correlation Coefficient}

It is very important to determine the relationship direction and the degree and the statistical significance of this relationship in the interaction of two variables. Classical statistical methods are widely used to calculate the relationship between two or more variables, such as $\mathrm{x}$ and $\mathrm{y}$, and to define conventional data sets. However, classical statistical methods cannot manage uncertainties in the natural structure of data very well. Because the source of uncertainties in the natural structure of the data affects many factors. We can define the uncertainties in the natural structure of the data with fuzzy measurements and mathematically express the measurements in each step. For example, if the correlation coefficient is calculated for a fuzzy data set, then 
the assumption that the independent variable $(\mathrm{X})$ is the same for all values in defining the inherent ambiguities between the two variables can be assumed.

The fuzzy logic theory calculates the degree of linear relationship between fuzzy sets with a certain degree of membership, resulting in more reliable and consistent results (Xie \& Wu 2012; Yang 2016). DingAn Chiang and Nancy P. Lin (1999) developed a crisp correlation coefficient between two fuzzy sets. The crisp correlation coefficient lies in the interval $[-1,1]$. Their method takes a random sample from a crisp set, with corresponding pairs of membership functions of the two fuzzy sets to compute the correlation between those two fuzzy sets. This method developed demonstrates not only the strength of the relationship between fuzzy sets, but also whether the relationship between fuzzy sets are positive (increasing) or negative (decreasing) (Lin et al 2007). A graphical representation of a fuzzy triangle number type data set is as shown in Figure 1 (Yongshen 2005).

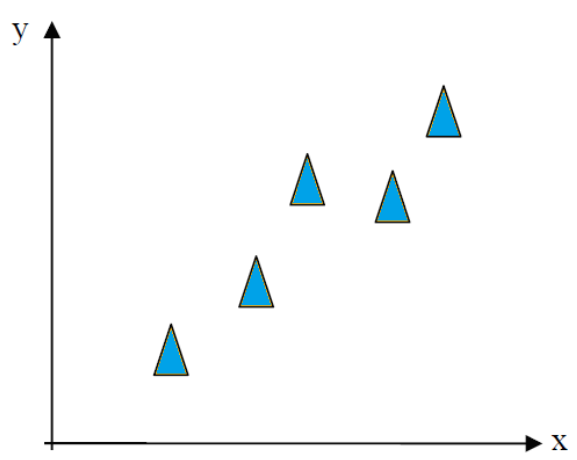

Figure 1

A blurred data set with a triangle membership function

The relationship between two fuzzy clusters such as $\widetilde{A}$ and $\widetilde{B}$ is linear as in classical clusters. The value that determines the degree of this linear relationship is also called the fuzzy correlation coefficient and can be shown in the form of $\widetilde{A}=\left\{x_{i}, \mu_{\widetilde{A}}\left(x_{i}\right) \mid x \in X\right\}$ and $\widetilde{B}=$ $\widetilde{\mathrm{A}}=\left\{\mathrm{x}_{\mathrm{i}}, \mu_{\widetilde{\mathrm{B}}}\left(\mathrm{x}_{\mathrm{i}}\right) \mid \mathrm{x} \in \mathrm{X}\right\}$. Fuzzy correlation coefficient $\tilde{\mathrm{r}}_{\mathrm{A}, \mathrm{B}}$ is calculated with the help of Equation (7) (Arnold 1990; Chiang \& Lin 2000). There must be at least two different fuzzy sets for the implementation of Equation 7. If fuzzy correlation coefficient $\widetilde{\mathrm{r}}_{\mathrm{A}, \mathrm{B}}>0 ; \widetilde{\mathrm{A}}$ and $\widetilde{\mathrm{B}}$ fuzzy sets are positively related, and the fuzzy correlation coefficient value for membership values is $\tilde{\mathrm{r}}_{\mathrm{A}, \mathrm{B}}=$ 1 (Yu 1993; Chiang \& Lin 2000).

If the value of the fuzzy correlation coefficient $\widetilde{\mathrm{r}}_{\mathrm{A}, \mathrm{B}}<0, \widetilde{\mathrm{A}}$ and $\widetilde{\mathrm{B}}$ The relationship between fuzzy sets is negative. If value of fuzzy correlation coefficient $\widetilde{\mathrm{r}}_{\mathrm{A}, \mathrm{B}}=0$, there is no correlation between $\widetilde{\mathrm{A}}$ and $\widetilde{\mathrm{B}}$ fuzzy sets and the value of the fuzzy correlation coefficient for the membership values of the non-cluster members is $\tilde{\mathrm{r}}_{\mathrm{A}, \mathrm{B}}=0$. Intermediate values that are not included in the set are the values of the fuzzy correlation coefficient, which is calculated by using the equation of uncertainty (5) and the equation (8) $0 \leq \mu_{\widetilde{\mathrm{A}}, \widetilde{\mathrm{B}}}\left(\mathrm{x}_{\mathrm{i}}\right) \leq 1$ receives very different membership levels (Yu 1993; Chiang \& Lin 1999; Lin et al 2007).
The formula used in this study is Pearson's product sum correlation coefficient; a pair of membership function values replaces the original data values as follows.

$$
\begin{aligned}
& \bar{\mu}_{A}=\frac{\sum_{i=1}^{n}\left(\mu_{A}\left(x_{i}\right)\right.}{n} \text { and } \bar{\mu}_{B}=\frac{\sum_{i=1}^{n}\left(\mu_{B}\left(y_{i}\right)\right.}{n} \\
& \tilde{S}_{A}^{2}=\frac{\sum_{i=1}^{n}\left(\left(\mu_{A}\left(x_{i}\right)-\bar{\mu}_{A}\right)^{2}\right.}{n-1} \text { and } \tilde{S}_{B}^{2}=\frac{\sum_{i=1}^{n}\left(\left(\mu_{B}\left(x_{i}\right)-\bar{\mu}_{B}\right)^{2}\right.}{n-1} \\
& \tilde{S}_{A}=\sqrt{\tilde{S}_{A}^{2}} \Rightarrow \tilde{S}_{A}=\sqrt{\frac{\sum_{i=1}^{n}\left(\left(\mu_{A}\left(x_{i}\right)-\bar{\mu}_{A}\right)^{2}\right.}{n-1}} \text { and } \\
& \tilde{S}_{B}=\sqrt{\tilde{S}_{B}^{2}} \Rightarrow \tilde{S}_{B}=\sqrt{\frac{\sum_{i=1}^{n}\left(\left(\mu_{B}\left(x_{i}\right)-\bar{\mu}_{B}\right)^{2}\right.}{n-1}} \\
& \tilde{\mathrm{r}}_{A, B}=\frac{\frac{\sum_{i=1}^{n}\left(( \mu _ { A } ( x _ { i } ) - \overline { \mu } _ { A } ) x \sum _ { i = 1 } ^ { n } \left(\left(\mu_{B}\left(x_{i}\right)-\bar{\mu}_{B}\right)\right.\right.}{n-1}}{\sqrt{\frac{\sum_{i=1}^{n}\left(( \mu _ { A } ( x _ { i } ) - \overline { \mu } _ { A } ) ^ { 2 } x \sum _ { i = 1 } ^ { n } \left(\left(\mu_{B}\left(x_{i}\right)-\bar{\mu}_{B}\right)^{2}\right.\right.}{n-1}}} \\
& \tilde{r}_{A, B}=\frac{\frac{\sum_{i=1}^{n}\left(\left(\mu_{A}\left(x_{i}\right)-\bar{\mu}_{A}\right) x\left(\mu_{B}\left(x_{i}\right)-\bar{\mu}_{B}\right)\right.}{n-1}}{\tilde{S}_{A} * \tilde{S}_{B}}
\end{aligned}
$$

(Chiang \& Lin 1999; Chiang \& Lin 2000; Lin et al 2007; Yongshen \& Cheung 2003). Here,

$\mu_{\widetilde{A}}\left(x_{i}\right)$ : the membership function, which expresses the equivalent of $x$ exact numbers in a fuzzy set such as $\widetilde{A}$, $\mu_{\widetilde{B}}\left(x_{i}\right)$ : the membership function, which expresses the equivalent of $\mathrm{x}$ exact numbers in a fuzzy set such as $\widetilde{B}$ $\sim$ : represents values for fuzzy sets.

$\bar{\mu}_{\widetilde{A}}$ and $\bar{\mu}_{\widetilde{\mathrm{B}}}: \widetilde{\mathrm{A}}$ and $\widetilde{\mathrm{B}}$ mean values of membership functions of fuzzy sets,

$\widetilde{S}_{A}$ and $\widetilde{S}_{B}: \widetilde{A}$ and $\widetilde{B}$ shows the standard deviation values of the averages of membership functions of fuzzy sets (Chiang \& Lin 1999).

Graphical fuzzy Perason correlation coefficient values are as in Figure 2 (Yongshen 2005).

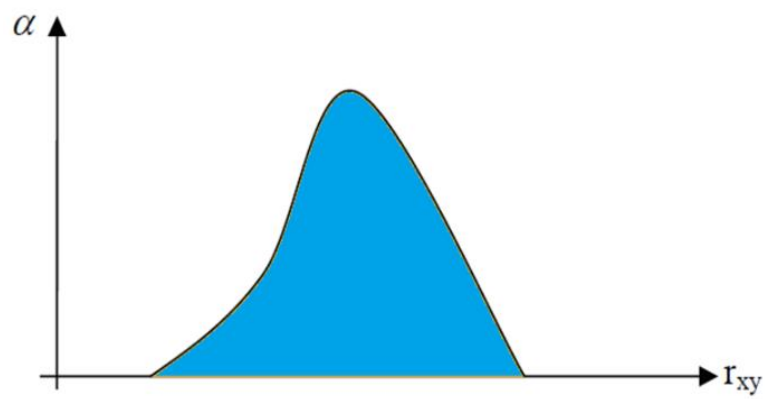

Figure 2

The fuzzy Pearson correlation coefficient values with the membership degrees

Fuzzy hypothesis testing for significance testing of fuzzy Pearson correlation coefficients can be established as follows (Buckley 2006).

$$
\mathrm{H}_{0}: \overline{\widetilde{\mu}}=0 \text { and } \mathrm{H}_{1}: \overline{\widetilde{\mu}} \neq 0
$$

Here; $\overline{\widetilde{\mu}}$ is the average of fuzzy Pearson correlation coefficients.

The hypothesis control of fuzzy Pearson correlation coefficients and the test statistic to be used for estimation of confidence limits are $\tilde{t}$ test (Buckley 2006). Test 
statistics for hypothesis testing are obtained in Equation (9) (Arnold 1990; Chiang \& Lin 2000; Yongshen 2005).

$\tilde{\mathrm{t}}=\frac{\tilde{\mathrm{r}}_{\mathrm{A}, \mathrm{B}}-\overline{\widetilde{\mu}}}{\tilde{\mathrm{S}}_{\mathrm{r}}} \mathrm{t}_{\mathrm{n}-2}, \frac{\alpha}{2}$

Here; $\widetilde{\mathrm{S}}_{\mathrm{r}}$ : is the fuzzy standard error value, supplied with:

$\tilde{S}_{\mathrm{r}}=\sqrt{\frac{1-\tilde{r}_{A, B}^{2}}{n-2}}$

For estimation of confidence limits;

$\overline{\widetilde{\mu}}=\tilde{\mathrm{r}}_{\mathrm{A}, \mathrm{B}} \pm \tilde{\mathrm{t}}_{\frac{\alpha}{2}} ; \widetilde{\mathrm{S}}_{\mathrm{r}}$

equality is used. Fuzzy Pearson correlation coefficient $\tilde{\mathrm{r}}_{\mathrm{A}, \mathrm{B}}$ of \%95 confidence interval is estimated as in Equality (11) (Arnold 1990; Chiang \& Lin 2000; Buckley 2006).,

$\tilde{\mathrm{r}}_{\mathrm{A}, \mathrm{B}}-\tilde{\mathrm{t}} \frac{\alpha}{2} ; \tilde{\mathrm{S}}_{\mathrm{r}}<\overline{\widetilde{\mu}}<\tilde{\mathrm{r}}_{\mathrm{A}, \mathrm{B}}+\tilde{\mathrm{t}} \frac{\alpha}{2} ; \tilde{\mathrm{S}}_{\mathrm{r}}=1-\alpha$

The fuzzy Pearson correlation coefficient calculated with Equation 8 shows the power and the distribution of the relationship between random variables $(\mathrm{Ni} \&$ Cheung 2003; Lin et al 2007). For this correlation method, the values of the correlation coefficient will be in the interval [-1, 1] (Chiang \& Lin 1999). As we have just described, the resultant correlation is a crisp value. A major contribution of this model is the development of partial correlation of fuzzy sets. If a random sample with multiple fuzzy attributes, Chiang and Lin's method can compute the correlation coefficient between the two fuzzy attributes.

\section{Results and Discussion}

For the estimation of lactation milk yield for each animal, the age of the animal at lactation (days) $\left(\mathrm{X}_{1}\right)$, number of days milked $\left(\mathrm{X}_{2}\right)$, service period (days) $\left(\mathrm{X}_{3}\right)$, the first calving age (days) $\left(\mathrm{X}_{4}\right)$, to measure whether the assumption of normality is realized, Shapiro-Wilk test was applied. The level of relationships between variables, lactation milk yield $(\mathrm{kg})\left(\mathrm{Y}_{\mathrm{i}}\right)$ with values $\left(\mathrm{X}_{1}\right),\left(\mathrm{X}_{2}\right),\left(\mathrm{X}_{3}\right),\left(\mathrm{X}_{4}\right)$, confidence levels for

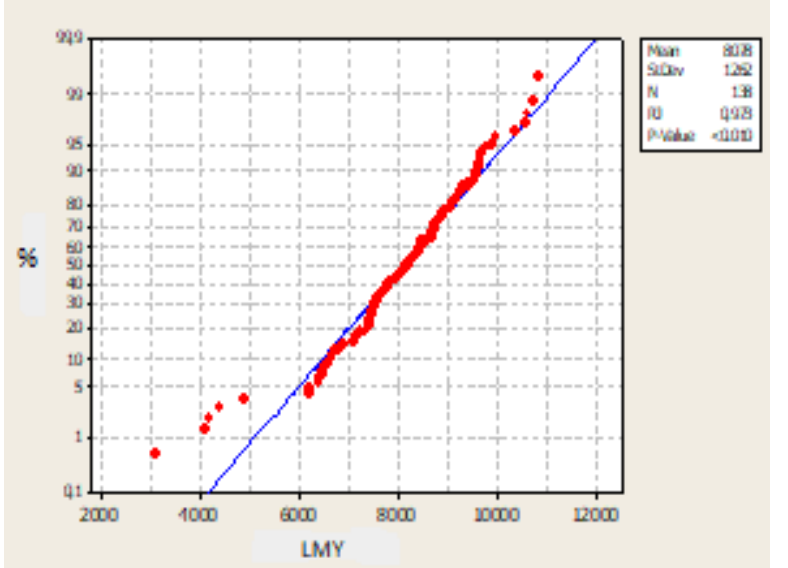

Figure 3

Lactation milk yield (LMY) relationship coefficients was calculated by fuzzy Pearson coefficient calculation methods. Relationship coefficients were compared by interpreting the confidence intervals.

In addition to the variables that are thought to affect lactation milk yields, it is tried to determine whether there are independent variables or not, and there are many related researches conducted and carried out. The results of these studies eliminate many uncertainties for producers. In order to solve many uncertainties related to lactation milk yields, the dependent and independent variables were defined and various equations were created.

Table 1

Descriptive statistics on lactation milk yield and reproductive characteristics(Topuz, 2018)

\begin{tabular}{lc}
\hline Variables & $\overline{\mathrm{X}} \mp \mathrm{S}_{\overline{\mathrm{X}}}$ \\
\hline $\operatorname{LMY}\left(\mathrm{Y}_{\mathrm{i}}\right)$ & $8078 \pm 107$ \\
$\operatorname{Age}\left(\mathrm{X}_{1}\right)$ & $1314 \pm 32.1$ \\
$\operatorname{DIM}\left(\mathrm{X}_{2}\right)$ & $326.69 \pm 1.19$ \\
$\operatorname{SP}\left(\mathrm{X}_{3}\right)$ & $173.77 \pm 2.49$ \\
FCA $\left(\mathrm{X}_{4}\right)$ & $745.25 \pm 1.69$ \\
\hline
\end{tabular}

(LMY: lactation milk yield, Age: the age of the animal at lactation, DIM: days in milked, SP: service period (days), FCA: first calving age (days).

To determine whether the assumption has normality, Shapiro-Wilk test was applied. When performing normality tests, the control $\left(\mathrm{H}_{0}\right)$ and the opposite $\left(\mathrm{H}_{1}\right)$ hypotheses are established as follows:

$\mathrm{H}_{0}$ : The data shows normal distribution.

$\mathrm{H}_{1}$ : Data do not show normal distribution.

When the hypothesis control $\left(\mathrm{H}_{0}\right)$ was accepted as a result of the hypothesis control ( $p>0.05$ ), it was concluded that the data showed normal distribution. Shapiro-Wilk normality tests were performed for lactation milk yields, service period and first calving age, and it was determined that these characteristics did not show normal distribution (Figure 3, Figure 4, Figure 5, Figure 6, Figure 7).

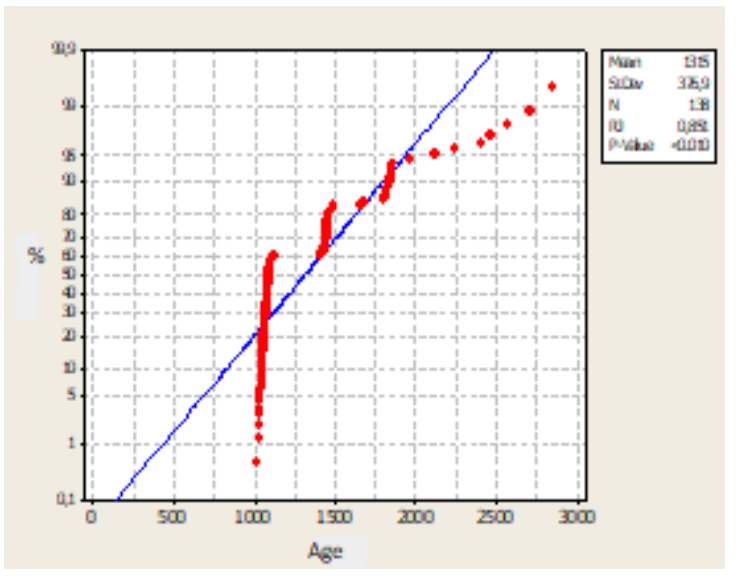

Figure 4

Normality tests for the age of the animal at lactation(Age) 


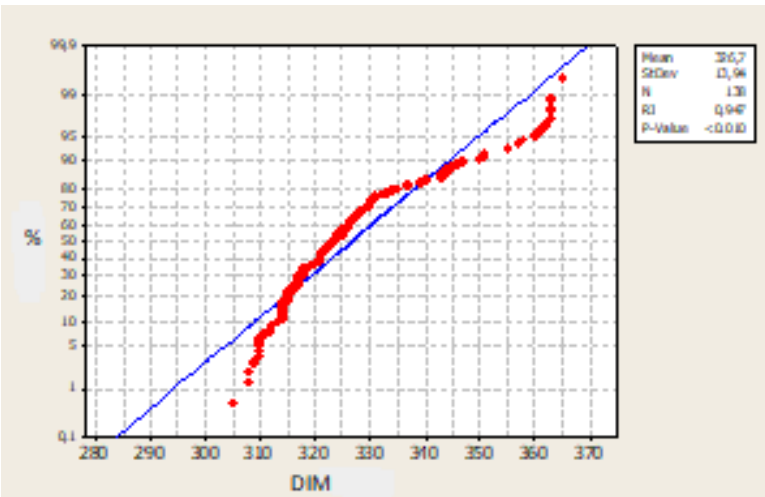

Figure 5

Normality tests days in milked (DIM)

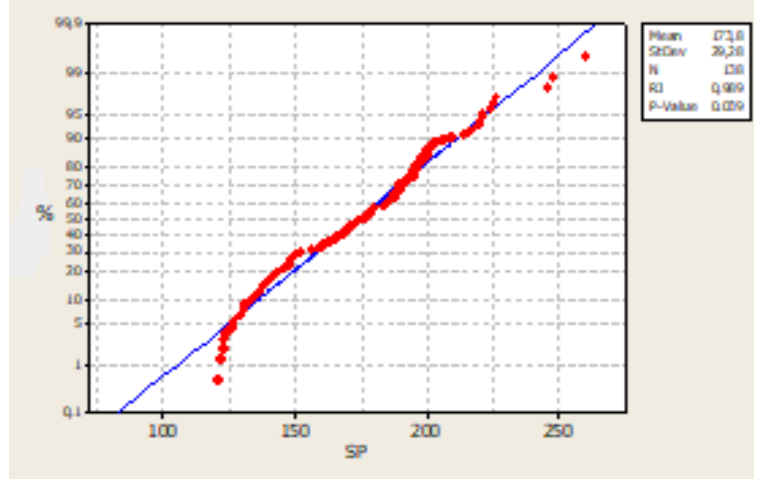

Figure 6

Normality tests for service period (SP)

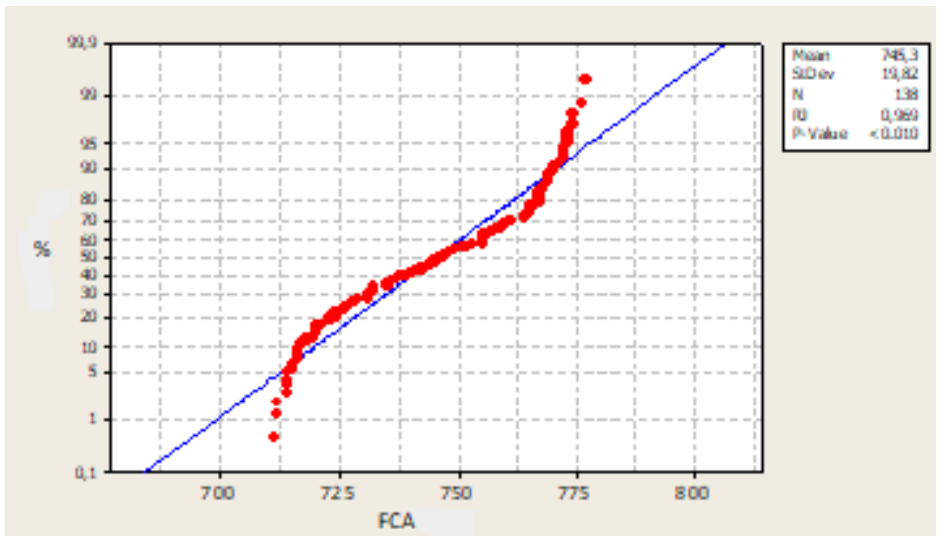

Figure 7

Normality tests for the first calving age (FCA)

In order to calculate the fuzzy Pearson correlation coefficient values and related statistics, Equation (8),
Equation (9), Equality (10) and Equation (11) were applied and the values in Table 2 were obtained.

Table 2

Statistics on the classical Pearson and fuzzy Pearson correlation coefficient values between lactation milk yield and reproductive characteristics

\begin{tabular}{|c|c|c|c|c|c|c|}
\hline Methods & Variables & $\mathrm{r}$ & $\mu(x)$ & $\mathrm{SE}$ & $\mathrm{t}$ & $\mathrm{CI}$ \\
\hline \multirow{4}{*}{ 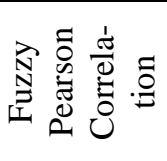 } & $\operatorname{Age}\left(X_{1}\right)$ & -0.0056 & 0.95 & 0.144 & 0.027 & $(-0.006)-(0.017)$ \\
\hline & $\operatorname{DIM}\left(\mathrm{X}_{2}\right)$ & 0.1419 & 0.98 & 0.206 & 0.688 & $(-0.155)-(0.438)$ \\
\hline & $\mathrm{SP}\left(\mathrm{X}_{3}\right)$ & -0.272 & 1.0 & -1.36 & 0.200 & $(-0.296)-(0.840)$ \\
\hline & $\mathrm{FCA}\left(\mathrm{X}_{4}\right)$ & -0.2543 & 0.90 & 0.200 & -0.270 & $(-0.277)-(0.785)$ \\
\hline
\end{tabular}

${ }^{* *}: \mathrm{P}<0.01$ (r: correlation coefficient, $\mu(\mathrm{x})$ : degree of membership, SE: standard error, t: test value, CI: confidence interval)

As can be seen from Table 2, the fuzzy correlation coefficient value between lactation milk yield and the age of the animal at lactation was calculated as 0.0056 , and the data of the calculated coefficient value was found to be represented by a membership degree close to one as high as $0.95(95 \%)(\mathrm{p}<0.01)$ (Table 2 and Figure 8). The fuzzy correlation coefficient value between lactation milk yield and the number of days milked was calculated as 0.1419 , and the data of the calculated coefficient value was found to be represented by a membership degree close to one as high as 0.98 $(98 \%)(\mathrm{p}<0.01)$ (Table 2 and Figure 9). The fuzzy correlation coefficient value between lactation milk yield and service period was calculated as -0.272 , and the data of the calculated coefficient value was found to be represented by a membership degree close to one as high as $1.0(100 \%)(\mathrm{p}<0.01)$ (Table 2 and Figure 10). The fuzzy Pearson correlation coefficient value between lactation milk yield and the first calving age was calculated as -0.2543 and the calculated coefficient value was represented with a membership degree of 0.9 (90\%) (Table 2 and Figure 11) (Topuz, 2018).

The distributions of the calculated fuzzy Pearson correlation coefficients with their membership degrees are similar to the graphs obtained from the study of Yongshen (2005). In the graphs, the vertical axis shows $\mu_{\widetilde{\mathrm{A}}, \widetilde{\mathrm{B}}}\left(\mathrm{x}_{\mathrm{I}}\right)$ degrees, and the horizontal axis shows the calculated Pearson correlation coefficients $\tilde{\mathrm{r}}_{\mathrm{A}, \mathrm{B}}$. 


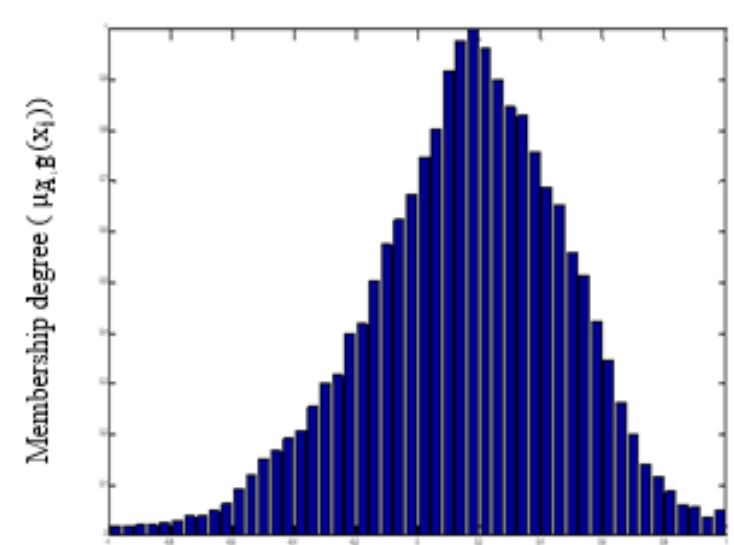

Fuzzy Pearson correlation coefficient values ( $\left.\tilde{\mathrm{r}}_{\mathrm{A}, \mathrm{B}}\right)$

Figure 8

Distribution of fuzzy Pearson correlation coefficients between lactation milk yield and the age of the animal at lactation and membership degrees

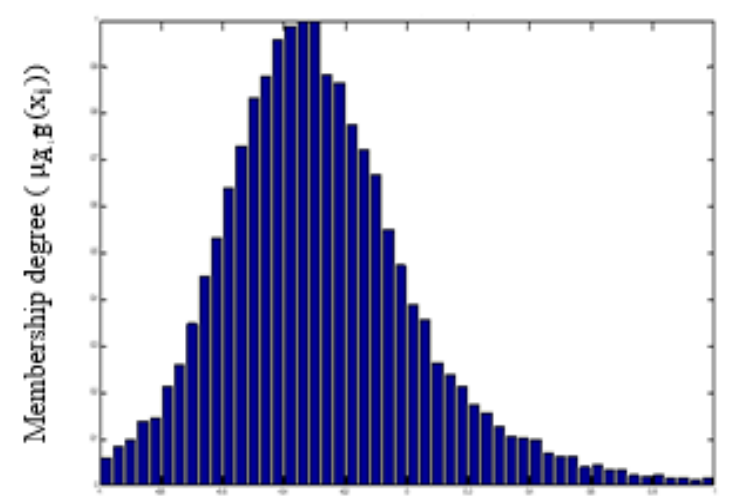

Fuzzy Pearson correlation coefficient values $\left(\tilde{\mathrm{r}}_{\mathrm{A}, \mathrm{B}}\right)$

Figure 10

Distribution of fuzzy Pearson correlation coefficients between lactation milk yield and service period and membership degrees

In cases where the data do not show normal distribution, it is possible to obtain more reliable and consistent results by calculating the fuzzy Pearson correlation coefficient value which can be calculated instead of classical Pearson correlation coefficient value. Researchers misinterpret by thinking that there is a strong relationship between the variables considering the sizes of the relationship coefficients calculated in this kind and similar studies. In order to calculate real and reliable relationship coefficients Matlab codes are created in our study.

\section{Conclusion and Suggestions}

Pearson's product-sum formula has been widely accepted to compute the correlation coefficient between two crisp random variables. In recent years, changing problems in daily life according to the conditions and continuous development of the research have led to more complex structure. The developments that have taken place during this time have revealed the necessity to change the standart analysis methods and perspectives depending on the development of science and technique. Fuzzy set theory is widely used in applica-

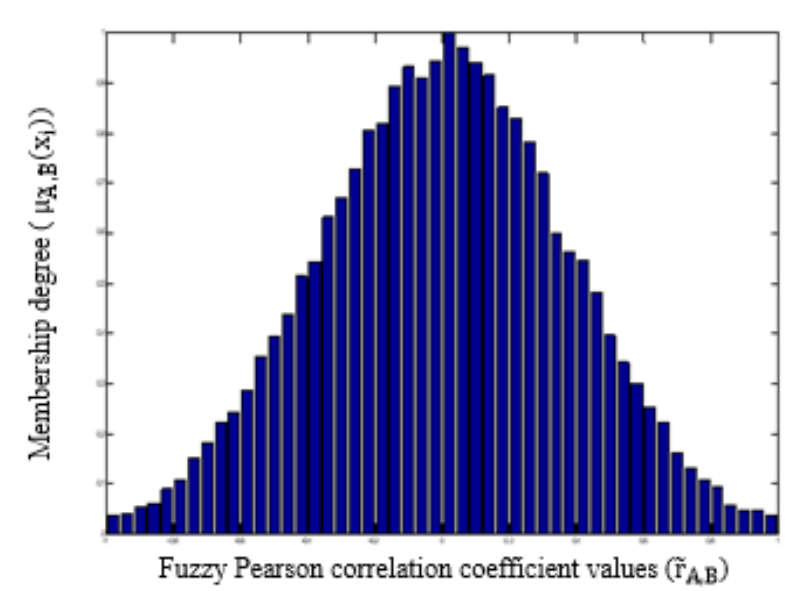

Figure 9

Distribution of fuzzy pearson correlation coefficients between lactation milk yield and number of days milked

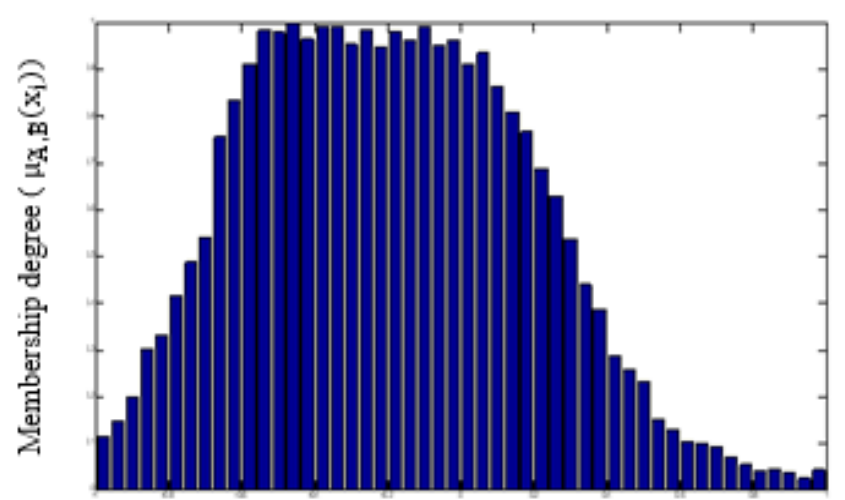

Fuzzy Pearson correlation coefficient values $\left(\tilde{\mathrm{r}}_{\mathrm{AB}}\right)$

Figure 11

Distribution of fuzzy Pearson correlation coefficients between lactation milk yield and first calving age

tions in different fields recently (Chiang et al 2004). However, one of the fuzzy logic approaches in practice is the fuzzy Pearson correlation coefficient, which has been done to analyze the correlation of fuzzy data. For example, applications in many fields such as engineering, medicine, psychology, business, agriculture, pharmacy and veterinary medicine have been done. In this study, an easy method based on theoretical foundations of classical Pearson correlation coefficient was used. The range of the calculated fuzzy coefficient is a fuzzy number with interval $[-1,1]$, which consists with the classic range of Pearson correlation. In addition, it was found that the coefficient value calculated by the classical Pearson correlation method was the same as the coefficient values calculated with the fuzzy Pearson correlation method.

The aim of this study is to calculate the Fuzzy Pearson correlation coefficient value and membership degrees on the exact dataset using the written MATLAB codes.

It is observed that if the original data set is in symmetric shape, then the fuzzy correlation takes on roughly symmetric distribution; otherwise, the membership function of the fuzzy correlation is a skew distributed. 
In cases where the data used in the model contain uncertainty, the method works more efficiently. It is concluded that it is appropriate for researchers to use the fuzzy Pearson correlation coefficient method when they want to reach the approximate results with the information that does not make any certainty when deciding for any situation.

\section{Acknowledgement}

This research was prepared from the Ph.D Thesis (in Selçuk University) entitled "“'Use of Fuzzy Regression Models in Dairy Cattle" of the first author.

\section{References}

Arnold SF (1990). Mathematical Statistics. New Jersey. Prentice-Hall.

Abdalla HA (2012). Possibilistic logistic regression: In fuzzy environment. Lap Lambert Academic Publishing. Saarbrücken- Germany

Atanassov K (2012). On intuitionistic fuzzy sets theory. Studies In Fuzziness and Soft Computing, Berlin- Germany.

Bede B (2013). Mathematics of fuzzy sets and fuzzy logic. Springer, Heidelberg New York Dordrecht London.

Buckley JJ (2006). Fuzzy probability and statistics. Studies In Fuzziness and Soft Computing, Publ., No: 2, Springer, Berlin- Germany.

Chiang DA, Lin NP (1999). Corelation of fuzzy sets. Fuzzy Sets and Systems 102(2): 221-226.

Chiang DA, Lin NP (2000). Partial corelation of fuzzy sets. Fuzzy Sets and Systems 110(2): 209-215.

Chiang J.H, Yue S, Yin Z (2004). A new fuzzy cover approach to clustering. IEEE Transactions on Fuzzy Systems 12(2):199- 208.

Ding -An Chiang and Nancy P. Lin (1999). Correlation of fuzzy sets. Fuzzy Sets and Systems 102(2):221226.

Xie MC, Wu B (2012). The relationship between high schools students time management and academic performance: an application of fuzzy correlation. Educational Policy Forum 15(1): 157-176.

Nguyen HT, Wakler EA (2000). First course in fuzzy logic. 2nd edition. Chapman \& Hall/CRC. Boca Raton, FL, 1 January, NewYork, pp.359.

Lin NP, Chen JC, Chueh HE, Hao WH, Chang CI (2007). A fuzzy statistics based method for mining fuzzy correlation rules. WSEAS Transactions on Mathematic 11(6): 852-858.
Paksoy T, Yapıcı Pehlivan N, Özceylan E (2013). Bulanik küme teorisi. Nobel Akademik Yayıncılık, Ankara-Turkey. (in Turkish)

Ross TJ (2004). Fuzzy logic with engineering applications, John Willey and Sons Inc, Fuzyy Sets, Wiley- New York.

Trillas E, Eciolaza L (2015). Fuzzy logic studies in fuzziness and soft computing. Springer. ISBN 9783-319-14203-6.

Sakawa M (1993). Fuzzy sets and interactive multiobjective optimization. Plenum Pres, New York, $305 \mathrm{p}$.

Şentürk S, Aşan Z (2007). Correlation coefficient in fuzzy logic; an application in meterological events. Eskisehir Osmangazi University Journal Of Engineering And Architecture 20 (1):149-158.

Tanaka H (1997). Fuzzy data analysis by possibilistic linear models. Fuzzy Sets and Systems 24(3): 363375.

Tanaka H, Guo P (1999). Possibilistic data analysis for operations research. Physica-Verlag Heidelberg, New York.

Tansu A (2012). Fuzzy linear regression: fuzzy regression. Lambert Academic Publishing, Springer, Berlin- Germany.

Topuz D (2018). Use of Fuzzy Regression Models In Dairy Cattle. Selçuk University, Graduate School of Natural and Applied Sciences De-partment of Animal Science PhD. Thesis, Konya.

Yang CC (2016). Correlation coefficient evaluation for the fuzzy interval data. Journal of Business Research 69(6): 2138-2144.

Yu C (1993). Corelation of fuzzy numbers. Fuzzy sets and Systems 55(3): 303-307.

Yongshen N, Cheung JY (2003). Correlation coefficient estimate for fuzzy data. In Intelligent Systems Design And Applications, Publ. No: 23, BerlinGermany.

Yongshen N (2005). Fuzzy correlation and regression analysis. university of oklahoma graduate college; UMI number: 3163014.

Zimmermann HJ (1996). Fuzzy set theory and its applications, springer science+business media. 3rd Edition, Kluwer-Nijhoff, Boston, New York, pp. 203-240.

Zadeh LA (1965). Fuzzy sets. Information and Control 8(3): 338-353.

Zadeh LA (1978). Fuzzy sets as a basis for a theory of possibility. Fuzzy Sets and Systems 1(1): 3-28. 